\title{
Sustainability issues in innovative waste reduction technology adoption and assimilation
}

\author{
Israel Dunmade \\ Department of Environmental Sciences, Mount Royal University, Calgary, Canada
}

Email address:

idunmade@mtroyal.ca, israel_dunmade@yahoo.ca

\section{To cite this article:}

Israel Dunmade. Sustainability Issues in Innovative Waste Reduction Technology Adoption and Assimilation. International Journal of Environmental Protection and Policy. Vol. 1, No. 4, 2013, pp. 59-67. doi: 10.11648/j.ijepp.20130104.13

\begin{abstract}
Increasing number of innovative waste reduction technologies are continuously being developed across various industrial sectors. Adoption and assimilation of proven waste reduction technologies can lead to significant resource savings, cost reduction, protection of biodiversity, and environmental conservation. However, transfer and adoption of technologies either across industrial sectors or geographical jurisdictions may pose enormous challenges to the adopters. In this study, issues affecting successful adoption and assimilation of waste reduction technologies from developed countries to developing countries and from one industrial sector to another were examined. Potential solution based on empirical study were also proposed. The study involved extensive literature survey and analysis of adoption procedures used by a number of technology adopters observed. It was discovered that the sustainability of waste reduction technology adopted depends on the fitness of the technology to the overall corporate success strategy, its compatibility with the corporate culture, availability of enabling operational infrastructure, sustained socio-political interest, and lifecycle cost of the technology.
\end{abstract}

Keywords: Waste Reduction, Sustainability Issues, Technology Adoption, Lifecycle Cost, Ecological Impacts

\section{Introduction}

Manufacturing activities and crafts that transform materials into finished products always generate liquid, solid, and/or gaseous waste materials. The quantity of waste and the type of waste_ whether solid waste, liquid effluent or gaseous emission_ generated by a manufacturing process depends on its approach to transforming materials into finished products. Generally, processes that gradually remove material pieces from blanch tend to generate more waste than those that involve adding material pieces together. The size of material pieces removed at a time, the speed of removal, the ductility or the dryness of the material being worked on, as well as the medium in which the process is taking place determine whether it will be a solid waste, liquid effluent, or gaseous emission. Processes that remove comparatively large chunk of material at a time tend to generate solid waste that have to be disposed off in a landfill while those that remove fine particles at a high speed release the particles into the air. Processes that cut small pieces of materials in the liquid medium often discharge the waste as effluents. These secondary flow streams do not only create environmental problems but they represent losses of valuable materials and energy from the production process. These material losses necessitate huge investment in pollution control technologies, significant disposal cost, and increased environmental liabilities. All these losses, liabilities, and non-value adding investments reduce corporate profits [1].

For years, many manufacturing concerns do not bother about these losses as long as there were no regulations and incentives to do so. Many of them simply transfer these additional costs to the consumers. Those that are operating in lax and un-enforced environmental regulations' jurisdictions continue to release those wastes to the environment. Many of these releases have resulted in diseases, birth defects, deforestation, reduced biodiversity, ecosystems destruction, and other environmental concerns. The global threats of these environmental issues have pushed them to the forefront of political agenda around the world. It then becomes evident that the current pattern of our economic activities cannot be sustained for long without significant innovation. Consequently, the populace and governments that have to deal with these disasters are demanding from companies more innovative cleaner approaches to production of goods and services [2-4]. These demand for cleaner industrial activities led to development of policies and several research efforts aimed at eliminating 
or minimizing these material losses as well as their attendant socioeconomic and ecological impacts $[5,6]$. Consequently, increasing number of innovative waste reduction technologies are being developed to address these secondary flow streams across various industrial sectors and across geopolitical boundaries. As a result of these technological breakthroughs, corporate and political leaders (especially from developing countries) are becoming interested in acquiring these innovative waste reduction technologies [7]. However, historical and research reports on technology transfer across geopolitical boundaries over the years have shown mixed outcomes of such endeavour. Although there are significant scholarly activities have been reported on technology transfer, especially on agricultural technology adoption in developing countries, nothing have been found on sustainability issues affecting waste reduction technology adoption and assimilation. This study was undertaken to fill this scholarship gap. A brief explanation of the research process used in this study is discussed in section two of this paper. Key findings on waste reduction technologies are discussed in section three. Section four contains main sustainability issues affecting the adoption and assimilation of waste reduction technologies within and across industrial sectors as well as across geopolitical boundaries. How to address the highlighted sustainability issues is presented in section five before drawing conclusions on the study.

\section{Research Methodology}

The study involved an intensive literature review on types of waste reduction technologies adopted across various industrial sectors as well as across socioeconomic and geopolitical boundaries. It also involved participant observations and analysis of their technology acquisition procedure and management. Moreover, the reported findings in this paper came from analysis of a series of discussions with stakeholders across geopolitical boundaries and culture over a period of twenty years.

\section{Key Findings}

\subsection{Types of Waste Reduction Technologies}

This study revealed that strategies regarding waste minimization technologies vary in terms of where the focus is on the product lifecycle (Fig. 1). While some strategists, researchers, and technology developers concentrate their efforts on elimination or reduction of waste from the source, others attempt to address the issue by looking at how the waste generated will not be released into the environment but reused or recycled. Many scholars have reviewed waste reduction/minimization strategies and practices [1, 6, 8-14]. Waste reduction technologies' classification varies significantly. One of the classifications grouped waste reduction technologies into predominant or innovative waste reduction technologies. This grouping is based on their newness and how widespread they are being used. According to Gonzalez and Kelly (2006)[12], "Innovative technologies are treatment and conditioning technologies which are already proven but which are fairly new, relatively advanced, or not widely used. These are technologies that are typically highly efficient in terms of waste volume reduction. They deserve further evaluation and consideration for wider application. In otherwords, they are technologies which should be encouraged for wider distribution among other countries."

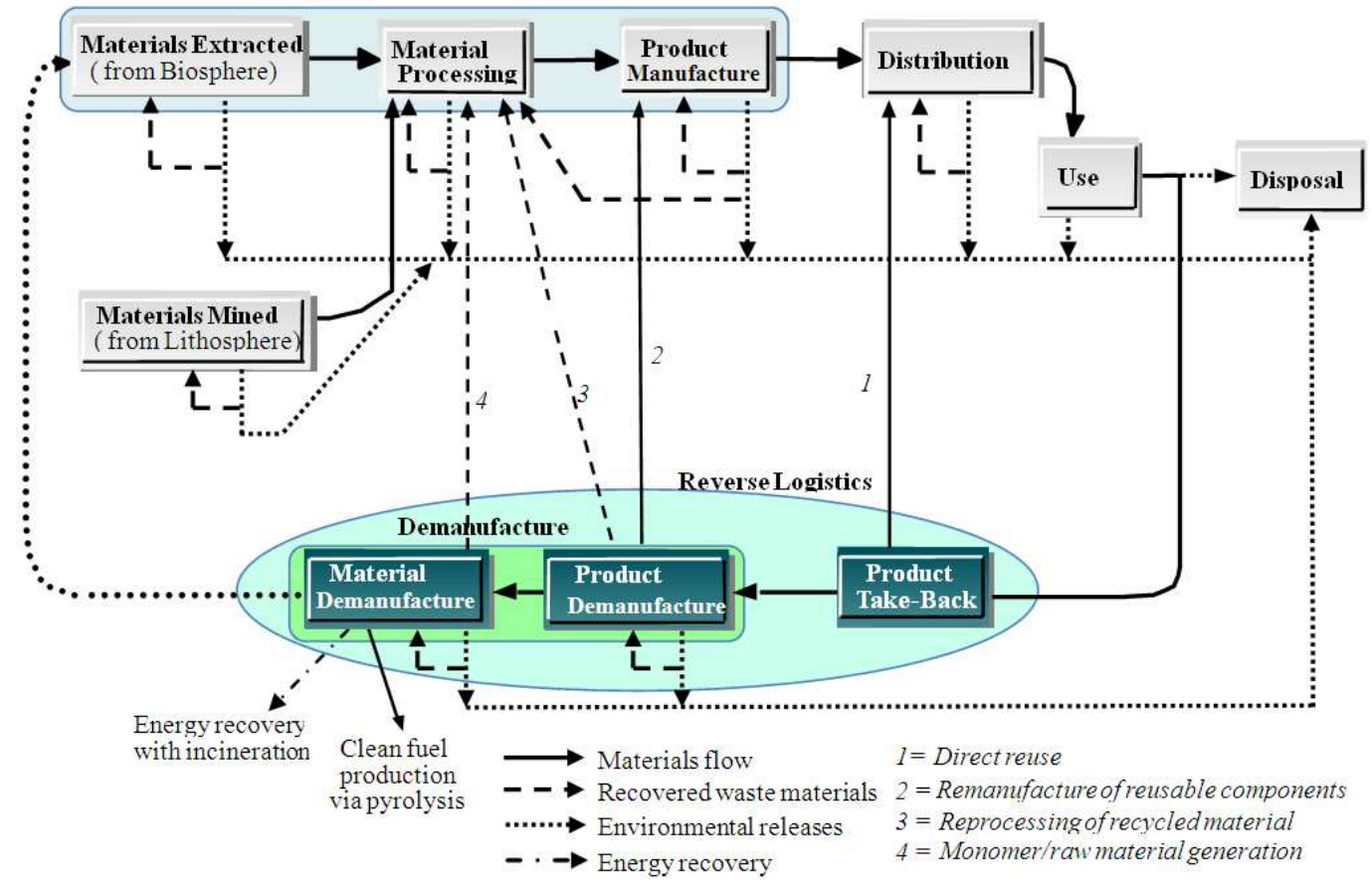

Figure 1. An illustration of waste reduction strategy/technology focus in the product lifecycle 
Commonly used innovative waste reduction approaches include source reduction by dematerialization, product reuse, remanufacturing, size reduction and separation, material recycling, composting, hydrolysis, pyrolysis, and incineration [15-20]. Innovative waste reduction technologies by dematerialization involve reducing the amount of materials that is used per unit output. We found that a lot of research efforts in this regard concentrate on product and process design and redesign. These design efforts include design for materials, design for minimum residues, design for packaging, and design for energy efficiency. Other manufacturing firms attempt to reduce their waste by focusing on developing their products that provide services to their consumers by leasing the products rather than selling the products. Consequently they use design for environment and cleaner production concepts in developing their products and manage their products throughout their products' service life with the customers. At the end of the service life of those products, the manufacturers retrieve them and they either upgrade or remanufacture them [21-22].

On the other hand, a number of innovative waste reduction technologies focus on facilitating the reuse of the product by other consumers for the same purpose or for a different purpose. Achievement of this goal is dependent on product configuration and process design. Product design for modularity and design for disassembly are particularly important to facilitate the reuse of product modules and component parts. Other waste reduction techniques are those that attempt to reduce the amount of waste released into the environment by facilitating the recycling of the waste generated. A number of such technologies focus on volume reduction and waste segregation. Others reduce wastes by incinerating, pyrolyzing and/or composting them to generate energy and products that can be used for other things. Some facilities combine the aforementioned techniques to optimize their waste minimization. Applicability and effectiveness of each specific approach depends on: i) the waste's characteristics, ii) socio-economic situation of the region of deployment, and iii) technical know-how of the region. "When searching for a solution to a problem related to a given waste stream, it is often economically beneficial to examine the technologies already existing within a given waste management system to see if they can be extended to that particular waste stream. This minimizes the number of technologies that has to be supported and, in doing so, will often minimize the cost of waste management" [12].

\subsection{Motivations for Investments in Waste Reduction Technologies}

There are many reasons why adopters invest in waste reduction technologies. One of them is because waste reduction leads to reduction in the cost of production and improved competitiveness [3]. Thus, by reducing wastes, corporate organizations save money not only by achieving savings from cost of materials but also by reducing the waste disposal costs. Another reason is to reduce environmental pollution and foster environmental health. In addition, the purpose may be to comply with state laws. Furthermore, organizations that proactively address the environmental and health concerns regarding their products stand to gain improved corporate image. Such corporate image improvement could come in the form of awards for excellence in resource use efficiency and waste reduction. Such awards could be by the state, by organizational groups, or by communities. Moreover, waste reduction could boost employees' morale. This could be as a result of the creation of healthy work environment. This would reduce absence from work, and increase productivity $[1,12,23]$.

\subsection{Waste Reduction Technologies Adoption and Assimilation Process}

Although the term adoption, and assimilation has been confused together in the literature. In this paper, technology adoption is defined as the stage in which a technology is selected for use by an individual or an organization [24]. An adoption process begins with awareness of the technology and its benefits. It progresses through the stage of assessment of usefulness and usability of the technology, and the ease or difficulty of adopting it. This is followed by the acceptance stage in which potential users decide to acquire and use the technology or decide not to adopt it. The acceptance stage is followed by the learning stage in which the user develops the skills and knowledge required to use the technology effectively. The adoption process is completed with the appropriate and effective usage of the technology [25]. On the other hand, technology assimilation is a series of stages from a firm's initial evaluation of the technology at the pre-adoption stage (initiation), through its formal adoption, and finally to its full scale adaptation and deployment. At the adaptation stage the technology becomes an integral part of the value chain activities (routinization) [26]. Consequently, technology adoption is like a subset of assimilation. Just like many other technologies, waste reduction technologies' adoption and assimilation require some considerations and installation of some essential infrastructure. This is particularly important because majority of the adopted waste reduction technologies were developed for in-house use. They were intended to meet specific needs of the organizations that developed them. Although most of them have had impressive record of success in achieving their intended purpose but performance results recorded at their place of origin were not repeated at some places of adoption because certain necessary steps were not taken or they were taken inappropriately $[27,28]$. The understanding of the importance and the need to find solutions to these problems have led to a lot of research interests in: i) determining the benefits and pitfalls of international technology transfer, ii) adaptability of transferred technology and factors that affect them, and iii) 
impacts of government policies on the exploitation of foreign sources of technologies [7]. This study looked at the technical, economic, socio-cultural, and ecological sustainability dimensions of the problems.

\section{Sustainability Issues in Waste Reduction Technology Adoption and Assimilation}

According to Zhang et al (2011)[29], “Achieving sustainable mission has become more urgent for all sectors of society." The sectors of the society also include waste reduction technology sub-sector of the economy. Sustainability in waste reduction technology adoption and assimilation has to do with: i) identification of potential waste minimization technologies for specific aspect of the economy, ii) taking appropriate steps to assess their level of technical, economic, socio-cultural, and ecological suitability for the intended deployment location, iii) taking decision and steps to acquire the adjudged best technology option, and (iv) internalizing and adapting the acquired technology. Successful implementation of all these steps in a way that will ensure the attainment of the desired sustainability require active involvement of all stakeholders. The involvement should be right from the point of conception through the re-incarnation of the technology in the same or entirely different form. Successful undertaking of these sustainability steps in assimilating innovative waste reduction technologies into a business or an economy also depend on adequate attendance to a number of issues, some of which are illustrated in Fig. 2 and discussed below [20, 30 - 35].

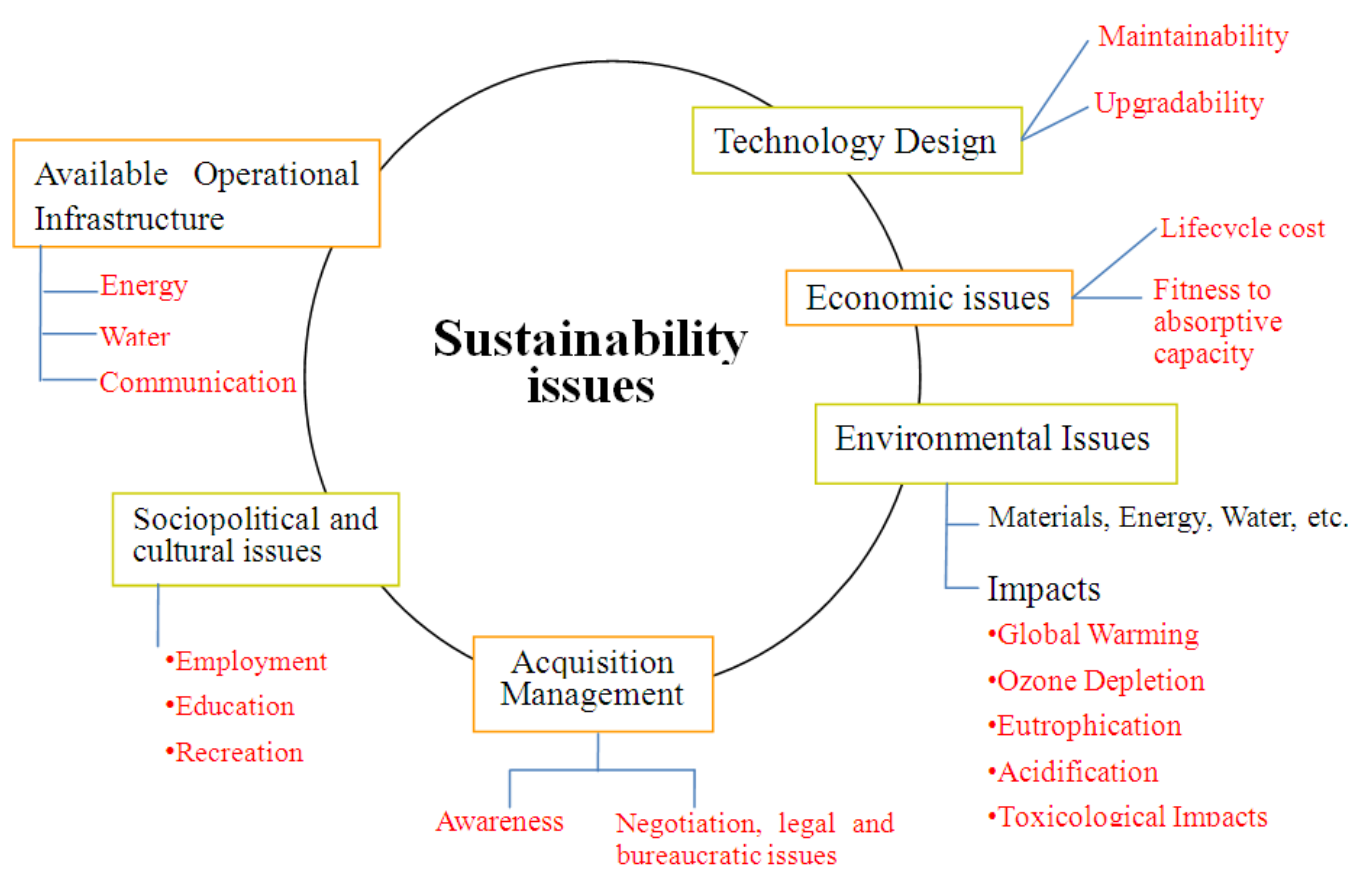

Figure 2. An illustration of Sustainability issues affecting waste reduction technology adoption and assimilation

\subsection{Technology Design}

Many of technologies acquired from another company/region were not originally planned to be transferred. Most of them were meant to meet the local needs and were thus designed with the consideration of the local prevailing conditions. Among the prevailing conditions often considered in technology design are operating capacity; available resource type, quantity and quality; available infrastructure for smooth operation of the technology, and operating/service environment where the technology will be deployed. Adequate consideration and incorporation of these factors in technology design and development often result in excellent technology performance. It is the success of such technologies that attract buyers. Unfortunately many of those technologies are simply purchased "off the shelf" and installed on the buyers' chosen sites without much consideration of the specific conditions of the sites where they will be used. Consequently, many of them record "epileptic success" while significant others failed to achieve any success at all.

\subsection{Economic Issues}

Acquisition costs of some waste reduction technologies are low but their operating and maintenance costs over their service lifetime are beyond the adopter's affordability. Observations revealed that some politicians and corporate leaders jump into technology acquisition because of their apparent comparatively lower capital outlay without thorough evaluation of the lifecycle economic implications of using the technology. Many of these leaders and/or their successors discover later that they cannot follow through with the completion of such projects or with operating those waste reduction technologies because of the huge 
financial commitment required before those technologies could yield any dividend on the investment. Such technologies are not economically sustainable for that corporation or that community. The study also revealed that the processing capacity of many adopted waste reduction technologies that suppose to fit into the economic stream of the firm or community were not adequately matched with the upper or lower part of the loop. This lack of adequate economic loop balancing has resulted in dysfunctional capacity utilization and the consequent economic burdens in many cases. There is therefore a need to assess the lifecycle economic suitability of the technology proposed for adoption [15, 23, 29, 36, 37].

\subsection{Environmental Issues}

One of the reasons for investing in waste reduction technology is to reduce negative ecological impacts of the economic activity on the environment. However, just like any other industrial activities, waste reduction technologies consume resources and generate emissions. The type and amount of resources consumed by each technology type and its environmental releases varies. Material and energy balance of some "so-called" waste reduction technologies revealed that they actually add to environmental problems rather than reducing it. It thus becomes necessary to evaluate the potential net environmental benefit that would result from adopting any waste reduction technology under consideration before taking steps to acquire it.

\subsection{Availability of Enabling Operational Infrastructure}

Many "ground breaking" inventions with a record of success at their place of origin have failed woefully in another country because the infrastructure required for successful utilization of that technology which exist at the origin was absent in the other place where it failed. It is therefore necessary to assess infrastructural requirement of a proposed waste reduction technology. The availability of the required infrastructure needs to be assessed in terms of its maximum capacity and the current level of its use. It is necessary to ensure that the current surplus capacity of the available infrastructure is equal or preferably more than what is required by the proposed waste reduction technology. It is also important to consider possible future expansion in the infrastructure as well as anticipate future needs for the same infrastructure for other things. This should be done in relation to the requirement of the proposed waste reduction technology in order to make adequate provision and planning for the sizing of the technology being considered for adoption [38]. Taking this step would ensure the availability and long service life of the waste reduction technology.

\subsection{Socio-Political and Cultural Issues}

This study revealed that potential cultural and recreational impacts of some waste management technologies were not "thought through" before their acquisition. It was after their installation and during operation that the enormity of their impacts was grasped and something had to be done about it. The fall out or the impending socio-political consequences of such impacts have led to an abrupt termination or shut down of some waste reduction technologies. Another socio-political issue is lack of continuity. Many laudable waste reduction projects have been abandoned at the ascent of a new political power or new management to the position of leadership. They were abandoned either because those projects are at variance with their political agenda or they are not on their list of priorities. The funding needed to complete or sustain the smooth running of such technologies is therefore diverted to another project(s) of interest. This is a big problem that would have to be solved especially in countries or companies where there are frequent changes of governments or management $[4,20$, 39].

\subsection{Acquisition Management}

This study revealed that some corporate and political leaders, not many, chose to acquire some waste reduction technologies without doing adequate due diligence in evaluating the suitability of the technology for the geographical location of intended use. It was discovered that some corporate leaders acted under pressure to avert regulatory or political penalty of not doing something about the waste problem at hand on time while others took the decision for personal rather than for the corporate/communal benefits. Lack of awareness of available options for satisfying the same need as well as non-availability of suitable information are other reasons for the wrong choice by some leaders. A number of representatives of technology adopting organizations fail to include appropriate clauses that would ensure the delivery of what is promised by the transferor. Consequently, poor negotiation, inadequate legal instrument, and disproportionate bureaucracy were other observed causes of failure for some adopted waste reduction technologies.

\section{Solution to Sustainability Issues in Innovative Waste Reduction Technology Adoption and Assimilation}

The following steps illustrated in Figure 3 and explained below are considered necessary to address/solve the problems identified in section 4 : 


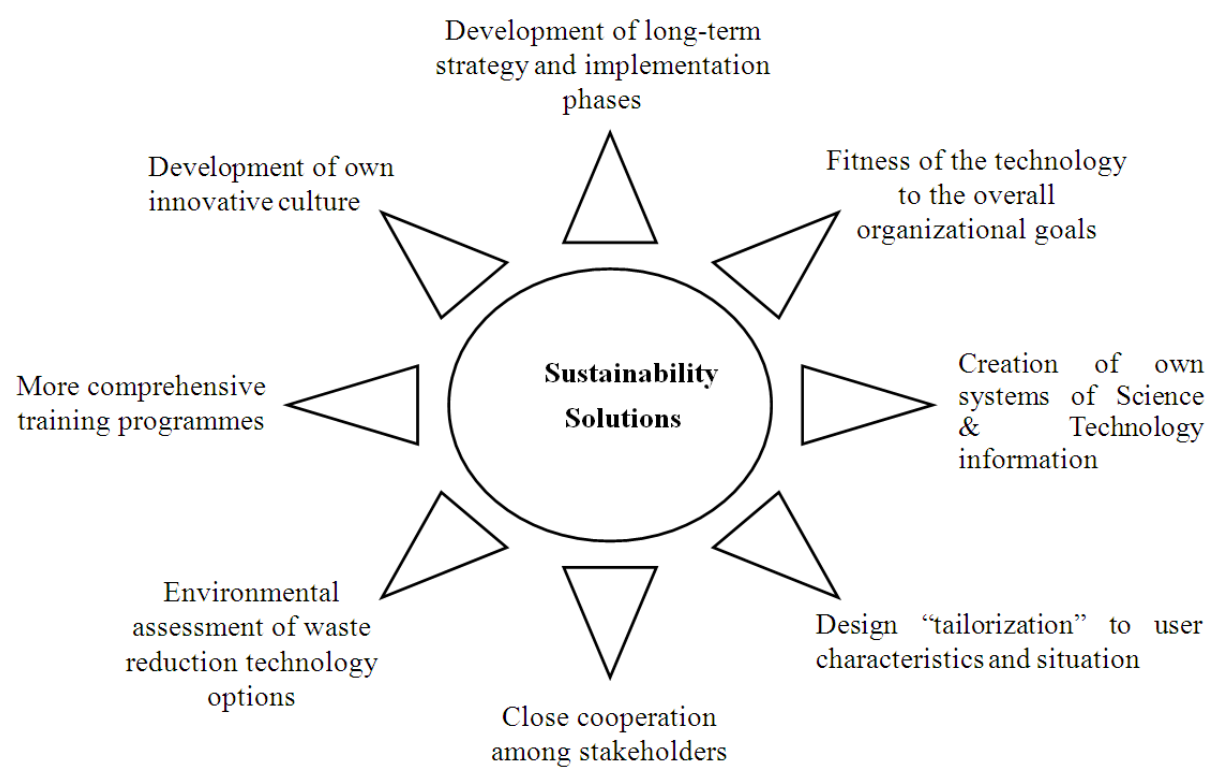

Figure 3. An illustration of solutions to sustainability issues in waste reduction technologies' adoption and assimilation

\subsection{Development of Long-Term Strategy and Implementation Phases}

Long term strategy on how to determine the kind of waste reduction technology that is needed and the process of its acquisition should be developed. Analytical framework should also be put in place to assess how and where the proposed technology will fit into the overall corporate success strategy or the economic development plan of the region. Check and balances should also be put in place to ensure a follow through $[4,40]$.

\subsubsection{Fitness of the Technology to the Overall Corporate/Economic Success Strategy}

Businesses exist to make profit. Corporations develop strategies on what to do, how to do it, and when to do what to do in order to achieve corporate profit goal. An organizations' achievement of its profitability goal(s) would determine the longevity of its existence and the retention of its management. The fitness of the technology to the overall corporate goal(s) and the lifespan of its management affect how much is invested in waste reduction and how long the management would continue to invest in waste reduction technology. Expected period of return on investment is another determining factor. As long as the waste reduction technology to be adopted fits into an organization's corporate success strategy, the adoption will be successful [41].

\subsection{Creation of Own System of Science and Technology Information}

Today, there are various ways of accessing necessary information about any subject of interest. We have print and electronic media of various types and levels of complexity. There are available databases and sources where newly developed technologies, their efficiencies, and other parameters can be accessed. Each corporate organization or community just need to select an information gathering system that meets its need and that is at its level of understanding [31, 42].

\subsection{Design "Tailorization" to User Characteristics and Situation}

Technology to be transferred should not be purchased off-shelf or copied in verbatim from the developer for the adopter. The technology should be adapted to suite the need of the adopter by considering the level of technical know-how of the user, capacity need of the adopter, and other prevailing local conditions where the technology will be deployed [43]. The configuration of a waste reduction technology in terms of its adaptability to the new service environment, maintainability, and upgradability to accommodate changing trend in the industry will affect whether it is sustainable over a long period of time or not. This is where the use of lifecycle design concepts is essential. It is important to make the waste reduction process simple enough for the adopter to understand how it works, be able to maintain the technology, and be able to adapt and improve the technology $[31,38]$.

\subsection{Close Cooperation of the Stakeholders}

Lack of cooperation between stakeholders has cost some countries a fortune in its bid to acquire technologies that could have helped it in attaining desired success in specific areas. Duplication of roles in agencies that suppose to work together was observed. It was discovered that some developers, vendors, and/or contractors exploited weaknesses of adopters to deliver inappropriate technologies and thereby illegally enriching themselves. It is believed that cooperation of all stakeholders will benefit everyone. There is therefore a need to educate and involve everyone right from the conception stage throughout the lifecycle of the project. 
This will eliminate waste, reduce suspicion and friction, lower the lifecycle cost, and lead to continuous improvement of the technology $[7,31,38]$.

\subsection{Environmental Assessment of Waste Reduction Technology Options}

Each waste reduction technology option being considered for adoption should be analyzed to determine the net environmental merits or demerits of deploying it at the adopter's location. The technology screening procedure described in Dunmade (2010)[38] can be used to assess the net environmental deficit or gain that would result from adopting a waste reduction technology.

\subsection{More Comprehensive Training Programmes}

Negotiating and regulatory officials as well as technocrats need more comprehensive training and regular/periodic retraining to handle changing intricacies of waste minimization technology transfer and adoption issues. Adaptation and implementation of training programmes to specific needs will reduce exploitation of the adopters, facilitate effective management of adopted technology, and improve the operational lifespan of the waste reduction technology [44].

\subsection{Development of Own Innovative Culture}

Culture affects many things that we do. Organizations and communities vary in their culture on how they communicate, maintain or manage issues or infrastructure. It also affects how we develop technology as we develop them to suite our way of life. Technologies that are significantly at variance with the way we do things may not be as successfully adopted as those that are compatible with how we live or handle issues. It is therefore necessary to evaluate waste reduction technology intended for adoption in relation to its compatibility with the national/ corporate culture before its acquisition. This research revealed that hybridization of indigenous technologies with the foreign technology of interest would be better than holistic copy and transfer of waste reduction technology that is foreign to a socio-cultural community. Doing so will reduce "techno-cultural" shock of imposing alien technology on the users, and increase users' sense of ownership and responsibility for the technology.

\section{Conclusion}

This study was focused on identification of sustainability issues affecting successful adoption and assimilation of waste reduction technologies. The study was necessary because of the huge investments directed at reducing negative impacts of our industrial activities on the environment and disappointing results obtained from a number of projects. Significant progress has been made at reducing the ecological footprint of our industrial activities, but transfer and adoption of these innovative waste reduction technologies from one company to another and from one country to another have not always been successful. Failure of some waste minimization projects have resulted in frustrations and finger pointing in some places. This study revealed some of the reasons why a number of those technology transfer and adoption efforts failed. It is believed that addressing the highlighted sustainability issues by using the suggested solutions would increase the success rate of waste reduction technologies adoption and put smiles on the faces of those that have committed their hard earn resources to waste reduction programs.

\section{References}

[1] WRT (Waste Reduction Technology), "Four Reasons Why Waste Reduction is Important to Your Company." Accessed on 4th April 2011 from http://www.wastereduction.org/

[2] M. Berry and E. Rondinelli, "Proactive corporate environmental management: A new industrial revolution," Academy of Management Executive, vol. 12(2), pp. 38-50, 1999.

[3] R.D. Klassen and D.C. Whybark, "The Impact of Environmental Technologies on Manufacturing Performance," The Academy of Management Journal, vol. 42 (6), pp. 599-615, 1999.

[4] S. Valentine, "The Green Onion: A Corporate Environmental Strategy Framework," Corporate Social Responsibility and Environmental Management, 2009, DOI: 10.1002/csr.21

[5] M.R.M. Crul; J.C. Diehl, and C. Ryan, "Design for Sustainability: A Step by Step Approach," United Nations Environment Programme, ISBN: 92-807-2711-7, 2009.

[6] G.E. Hunt, "Waste Reduction Techniques: An Overview," Pollution Prevention Review/Winter 1990-91. Accessed on 12 April 2011 from http://www.p2pays.org/ref/02/01036.pdf

[7] V. Wong; V. Shaw and P. Sher, "Effective Organization and Management of Technology Assimilation: The Case of Taiwanese Information Technology Firms," Industrial Marketing Management, vol. 27(3), pp. 213-227, 1998.

[8] N. Beaumont, and R. Tinch, "Abatement cost curves: a viable management tool for enabling the achievement of win -win waste reduction strategies?" Journal of Environmental Management, vol. 71(3), pp. 207-215, 2004.

[9] CEHI (Carribean Environmental Health Institute), "A directory of environmental waste reduction technologies." Accessed online http://www.cehi.org.lc/ESTDIRECTORY.pdf

[10] L.F. Diaz; G.M. Savage; L.L. Eggerth and L. Rosenberg, " Single-celled Protein and Ethanol Production," UNEP International Environmental Technology Centre, CalRecovery, Inc. Accessed online on 30 April 2011 at http://www.unep.or.jp/ietc/publications/spc/solid_waste_ma nagement/Vol_I/15-Chapter9.pdf

[11] J.D. Englehardt, "Pollution prevention technologies: A review and classification," Journal of Hazardous Material, vol. 35, pp. 119-150, 1993.

[12] J. Gonzalez and J. Kelly, "Innovative waste treatment and conditioning technologies at nuclear power plants." Accessed 
online

http://www-pub.iaea.org/MTCD/publications/PDF/te 1504 web.pdf

[13] S. Sthiannopkao and S. Sreesai, "Utilization of pulp and paper industrial wastes to remove heavy metals from metal finishing wastewater," Journal of Environmental Management, vol. 90(11), pp. 3283-3289, 2009.

[14] Zerbock, O. (2003). Urban Solid Waste Management: Waste Reduction in Developing Nations. Accessed on April 26 from $\mathrm{http}: / / w w w . c e e . m t u . e d u /$ sustainable engineering/resources/t echnical/Waste_reduction_and_incineration_FINAL.pdf

[15] E.J. Bakker; A.J. Berkhout,; L. Hartmann, and P.C. Rem, "Turning Magnetic Density Separation into Green Business Using the Cyclic Innovation Model," The Open Waste Management Journal, vol. 3, pp. 99-116, 2010.

[16] V.T. Dao and J.K. Kim, "Scaled-up bioconversion of fish waste to liquid fertilizer using a 5 L ribbon-type reactor," Journal of Environmental Management, doi:10.1016/j.jenvman.2011.05.003.

[17] M. El-Fadel; M. Zeinati; K. El-Jisr and D. Jamali, "Industrial-waste management in developing countries: The case of Lebanon," Journal of Environmental Management, vol. 61(4), pp. 281-300, 2001.

[18] B. González-Corrochano; J. Alonso-Azcárate, and M. Rodas, "Production of lightweight aggregates from mining and industrial wastes," Journal of Environmental Management, vol. 90(8), pp. 2801-2812, 2009.

[19] M. Hardie; G. Miller, and S. Khan, "Waste Minimisation in Office Refurbishment Projects: An Australian Perspective," The Open Waste Management Journal, vol. 4, pp. 21-27, 2011.

[20] X. Zhang; L. Shen; Y. Wu and G. Qi, "Barriers to Implement Green Strategy in the Process of Developing Real Estate Projects," The Open Waste Management Journal, vol. 4, pp. 33-37, 2011.

[21] J. Fujimoto; Y. Umeda; T. Tamura; T. Tomiyama and F. Kimura, "Development of Service-Oriented Products Based on the Inverse Manufacturing Concept," Environmental Science and Technology, vol. 37, pp. 5398-5406, 2003.

[22] W. Kerr, and C. Ryan, "Eco-efficiency gains from remanufacturing: A case study of photocopier remanufacturing at Fuji Xerox Australia," Journal of Cleaner Production, vol. 9 (10), pp. 75-81, 2001.

[23] J. Baldwin and Z. Lin, "Impediments to Advanced Technology Adoption for Canadian Manufacturers," Statistics Canada Paper 11F0019MPE No. 173, ISSN: $1200-5223$

ISBN: 0-662-30788-7, 2001.

[24] V.H. Carr , " Technology adoption and diffusion," Accessed on 28 December 2008 at http://tlc.nlm.nih.gov/resources/publications/sourcebook/ado ptiondiffusion.html

[25] BTTC, "What is Technology Adoption?" Accessed on 20 June 2011 http://www.bridges-to-technology.com/page21.html

[26] K. Zhu; K. Kraemer, and S. Xu, "The Process of Innovation Assimilation by Firms in Different Countries: A Technology
Diffusion Perspective on E-Business," Management Science, Vol. 52(10), p. 1557-1576, 2006.

[27] O.C. Eneh, "Technology Transfer, Adoption and Integration: A Review," Accessed on 4th April 2011 at docsdrive.com/pdfs/ansinet/jas/2010/1814-1819.pdf

[28] C. O'Neal; H. Thorelli, and J. Utterback, "Adoption of Innovation by Industrial Organizations," Industrial Marketing Management, vol. 2, pp. 235-250, 1973.

[29] H. Zhang; D. Zhang; T. Jin; P. He; Z. Shao, and L. Shao, "Environmental and economic assessment of combined biostabilization and landfill for municipal solid waste," Journal of Environmental Management, doi:10.1016/j.jenvman.2011.05.018.

[30] BGCI (Botanic Gardens Conservation International), "Agenda 21: Programme of Action for Sustainable Development," BGC News, vol. 3 (2), June 1999.

[31] N. Kim and R. Srivastava, "Managing Intraorganizational Diffusion of Technological Innovations," Industrial Marketing Management, Vol. 27, p. 229-246, 1998.

[32] D. Krajnc and P. Glavic, "How to compare companies on relevant dimensions of sustainability," J. Ecological Economics, Vol. 55, p. 551- 563, 2005.

[33] H. Muga and J.R. Mihelcic, "Sustainability of wastewater treatment technologies," Journal of Environmental Management, Vol. 88(3), p. 437-447, 2008.

[34] UNGA (United Nations General Assembly), "Global Conference on the Sustainable Development of Small Island Developing States," Bridgetown, Barbados, 25 April-6 May 1994. A/CONF.167/9

[35] V. Veleva and M. Ellenbecker, "Indicators of sustainable production: framework and methodology," Journal of Cleaner Production, vol. 9, pp. 519-549, 2001.

[36] E. Daniel, A. Myers and K. Dixon, "Don't Blame the Tools: The Adoption and Implementation of Managerial Innovations," Don't Blame the Tools, 2009, pp. 1-44. doi:10.1016/B978-1-85617-682-8.00001-1

[37] P. Stoneman and M. Kwon, "Technology adoption and firm profitability," The economic journal, vol. 106(437), pp. 952-962, 1996.

[38] I.S. Dunmade, "Collaborative lifecycle design - A viable approach to sustainable rural technology development," International Journal of Technology Management and Sustainable Development, vol 9(2), pp. 149-154, 2010.

[39] I.S. Dunmade, "Indicators of Sustainability: Assessing the Suitability of a Foreign Technology for a Developing Economy," Technology in Society, vol. 24(4), pp. 461-471, 2002.

[40] A. Generowicz; J. Kulczycka; Z. Kowalski and M. Banach, "Assessment of waste management technology using BATNEEC options, technology quality method and multi-criteria analysis," Journal of Environmental Management, vol. 92, pp. 1314-1320, 2011.

[41] T. Cooke-Davies, "The "real" success factors on projects," International Journal of Project Management, vol. 20, pp. 185-190, 2002.

[42] T. Conley and C. Udry, "Learning About a New Technology: 
Pineapple in Ghana," Accessed on 20 June 2011 at www.econ.yale.edu/ cru2/pdf/july2005a.pdf

[43] F. Batz; K. Peters and W. Janssen, "The influence of technology characteristics on the rate and speed of adoption," Agricultural Economics, vol. 21(2), pp. 121-130, 1999.
[44] A. Belout and C. Gauvreau, "Factors influencing project success: the impact of human resource management," International Journal of Project Management, vol. 22, pp.1-11, 2004. 